Epidermophytosis of Feet.-The interdigital spaces were thoroughly cleaned, and all dead skin removed; $0.5 \%$ P.M.C.calamine powder was applied if the affected area was very moist, and when drying had occurred $0.125 \%$ ointment was applied twice daily.

Epidermophyton Inguinale (Dhobi Itch). -A single application of ointment was used for four hours' contact. After thorough inunction into the affected area, paying special attention to the infected spreading edge, strips of lint coated with the ointment were applied to the lesion, and fixed in position with pads of cotton-wool and a double T-bandage. The skin became normal in five to six days.

Regarding epidermophyton infection of the toes, recurrences are mainly due to (1) fresh infection from an outside source; (2) reinfection from the patient's own socks or footwear. To overcome the latter, socks should be steeped for an hour in $1 / 20,000$ P.M.A. solution before washing; the boots or shoes can be treated by spraying the interior with a $1 / 2,000$ alcoholic solution of P.M.A.

Jungle Sores.-In forward areas and where the sores were small or of recent origin, compresses of $1 / 8,000$ P.M.A. were applied for 24 hours. This brought about complete disinfection of the sore. Elastoplast was then applied, after painting the surrounding skin with the solution, and very good results were obtained. In base areas, where large chronic sores were seen, the following technique was adopted. (1) Disinfection with $1 / 8,000$ compress of P.M.A. for 24 hours ; (2) normal saline compress for a further 24 hours ; (3) skin-grafting on the third day. In some of the early cases the grafts did not take well, and it was considered that excess of the $\mathrm{C}_{6} \mathrm{H}_{5} \mathrm{Hg}$ ion was the inhibiting factor. The saline lavage and compress for 24 hours did away with this side-effect. It is suggested (FitzGibbon) that a rapid lavage with a $1 \%$ thiourea solution would produce the same effect, as the - SH group in thiourea would neutralize any excess of the compound ion.

\section{Toxic Effects}

No cases of sensitivity to organo-mercurials were encountered. In some patients, especially those of fair or auburn colouring, slight and temporary vesication occurred, mainly around the spreading edges of the skin lesions. This disappeared in 24 to 48 hours, leaving a clean healthy skin beneath. There appears to be no possible danger of toxic effects due to absorption through the skin. The work of the U.S. External Products Research Institute has shown that the body can deal with daily several thousand gamma of $\mathrm{Hg}$ in the form of a soluble mercurial, and that the human skin absorbs only 1/3,800 of that applied to it (American Perfumer and Essential Oil Review, 1943 ; Stock, 1938). No dangerous mercury reservoirs are formed, as in the case of lead. Ten grammes of $0.125 \%$ P.M.C. contains about 6,000 gamma of $\mathrm{Hg}$, and the amount absorbed is minute. In this connexion it is interesting to note that all U.S. reconstituted plasma contains $12.5 \mathrm{mg}$. of phenyl mercuric borate to each $250 \mathrm{ml}$. unit; this is equivalent to about 8,000 gamma of $\mathrm{Hg}$. No toxic effects have been reported in cases which have had large plasma transfusions, in spite of the considerable intake of organic mercury.

\section{Summary and Conclusions}

A report is presented of the successful treatment of 500 cases of skin disease by organic mercurials.

It is pointed out that phenyl mercuric compounds in plant mycology are recognized as possessing specific and rapid fungicidal effects in high dilution, and that similar effects can be obtained in fungus infections in man.

The bactericidal potency of these compounds is extraordinarily high, and as surface antiseptics they were found to be extremely satisfactory.

The method of preparation is described, with the results of treatment in certain infections.

It must be emphasized that the method of application and duration thereof must be strictly adhered to in order to effect rapid cure.

The original report was pubiished by kind permission of Medical Directorate, G.H.Q., India Command, and acknowledgments were made to Col. P. D. Johnson, R.A.M.C., at whose unit most of the preliminary work was done. My thanks are also due to Mr. M. FitzGibbon, F.R.I.C., Lunevale Products, Lancaster, for generous
supplies of the organo-mercurials mentioned, and for helpful suggestions regarding certain technical details. I am also indebted to Mr. H. Fine, M.P.S., and to Mr. J. H. Croxon for their work in the preparation of the applications used, and their help in the carrying out of treatment.

\author{
REFERENCES
}

American Perfumer and Essential Oil Review, Aug., 1943.

Biskind, L. H. (1935). Lancet, 2, 1049.

Byrne, E. A. J., and Croxon, J. H. (1944). Indian med. Gaz., 69, 357.

Chick, H., and Martin, C. J. (1908). J. Hyg., Camb., 8, 698.

Hill, W. H. (1943). Canad. publ. Hith. J., 39, 158.

Hunter, D., et al. (1940). Quart. J. Med., n.s. 9, 193.

Paul, T., and Prall, F. (1907). Arb. ReichsgesundhAmt., 26, 73

Shaw and Montgomery (1941). E. Malling Research Station Report, 25. Shaw and Moore (1944). Ibid., 128 .

Stock (1938). Svenska Kennelkl. Tidskr., 50, 242.

Weed, L. A., and Ecker, E. E. (1933). J. infect. Dis., 62, 354.

Winslow, C. E. A., and Hotchkiss, M. (1922). Proc. Soc. exp. Biol., N.Y., 19, 314 Woodruff, L. L, and Bunzel, H. H. (1909). Amer. J. Physiol., 25, 190.

\section{Medical Memoranda}

\section{Lethane 384 on Glothing as a Mosquito Repellent}

In 1942 during field tests with various antimosquito repellents a few tests were carried out with "lethane 384." They were only preliminary tests and were never followed up, but they showed that lethane 384 applied locally to clothing-for example, stockings-may have its uses as a mosquito repellent in civil life when dimethyl phthalate either is not procurable or its use is undesirable because of its solvent properties on plastics, paint, etc. Lethane 384 is of course unsuitable as a skin application on account of its irritant and toxic properties.

\section{Method}

All tests were made in a wood at Brookwood, Surrey, during August, 1942. The mosquitoes biting were mainly Aedes cantans, Ae. punctor, Ae. annulipes, with an occasional Ae. cinereus, Ae. geniculatus, and Anopheles claviger. Treated volunteers and untreated controls sat together in the wood, usually for 15 minutes, and counted the number of bites experienced. Controls and treated men sat a few feet apart. There were two sets of experiments.

Test 1.-Men wore thin cotton stockings (A.T.S. issue), which were sprayed with $50 \%$ lethane $384(25 \%$ actual; solvent; a light oil ; spray base 775) from a hand-spray held at a distance of $1 \mathrm{ft}$. $(30 \mathrm{~cm}$.). Six pumps were given to the front and six to the back of the legs of each man- $23 \mathrm{ml}$. was used to spray four men. The men then rolled up their socks over the stockings at the ankles, pulled down the trouser legs of the battle dress and waited, strolling about, till the testing times. At the test, the trouser legs were rolled up above the knees and the socks turned over below the ankles, and the men sat on the bank of a dry ditch, together with controls (stockings untreated), and counted the mosquitoes which bit the legs from knee to ankle. The hands and face were covered with gloves and veils.

Test 2.-Men wore denim overalls, which were sprayed thoroughly all over so that the overalls could be seen to be wetted. The spray was held at a distance of about 18 in. $(45 \mathrm{~cm}$.). The mean dosage was not less than that delivered on the legs in the first test. In this test the sleeves were rolled up to above the elbow and the number of bites on hands and forearms were recorded. The exposed parts were in no way treated.

\section{Results}

Table I summarizes the results for sprayed stockings. The figures in brackets show the number of men in each group.

TABLE I

\begin{tabular}{|c|c|c|c|c|c|c|}
\hline \multirow{2}{*}{$\begin{array}{c}\text { Time } \\
\text { after } \\
\text { Spraying } \\
\text { (hours) }\end{array}$} & \multirow{2}{*}{$\begin{array}{c}\begin{array}{c}\text { Period of } \\
\text { Test } \\
\text { (mins.) }\end{array}\end{array}$} & \multicolumn{2}{|c|}{ No. of Bites } & \multicolumn{2}{|c|}{$\begin{array}{c}\text { Biting Rate } \\
\left(\begin{array}{c}\text { No. of bites in } \\
\text { control }=100 \%)\end{array}\right. \\
\end{array}$} & \multirow{2}{*}{$\begin{array}{c}\% \\
\text { Protection } \\
\text { Treated }\end{array}$} \\
\hline & & Treated & Control & Treated & Control & \\
\hline $\begin{array}{l}1-1 \frac{1}{1+1} \\
4-4 \frac{1}{2} \\
5-5 \frac{1}{4} \\
5 t-5 \frac{1}{2}\end{array}$ & $\begin{array}{l}15 \\
15 \\
15 \\
15 \\
15\end{array}$ & $\begin{array}{ll}3 & (4) \\
1 & (4) \\
1 & (4) \\
6 & (4) \\
3 & (4)\end{array}$ & $\begin{array}{rr}6 & (4) \\
28 & (4) \\
35 & (4) \\
22 & (4) \\
19 & (4)\end{array}$ & $\left.\begin{array}{r}50 \\
3.6 \\
2.9 \\
27.3 \\
15.8\end{array}\right\} 22$ & $\begin{array}{l}100 \\
100 \\
100 \\
100 \\
100\end{array}$ & $\begin{array}{l}38.3 \\
97 \cdot 1 \\
78\end{array}$ \\
\hline & & 14 & $10(20)$ & 12. & 100 & \\
\hline
\end{tabular}

Stockings removed : rolled up and put on again next morning :
24 \begin{tabular}{l|ll|ll|l|l|l|} 
& 24 & (3) & 23 & (3) & $104 \cdot 3$ & 100 & Nil
\end{tabular}

No. of bites per man:

Mean .. of mean 0.70
0.2012 $5 \cdot 50$
$0 \cdot 7159$

Difference of means is statistically significant. 
It is evident that lethane on thin fabrics such as stocking material is a very effective repellent, and it has a useful effect for a number of hours. If a bigger dosage was given, probably an even higher degree of protection might ensue for a longer time.

The second test was made in order to see if a complete spraying of the clothing would protect exposed parts which were otherwise unprotected-for example, hands and face.

TABLE II

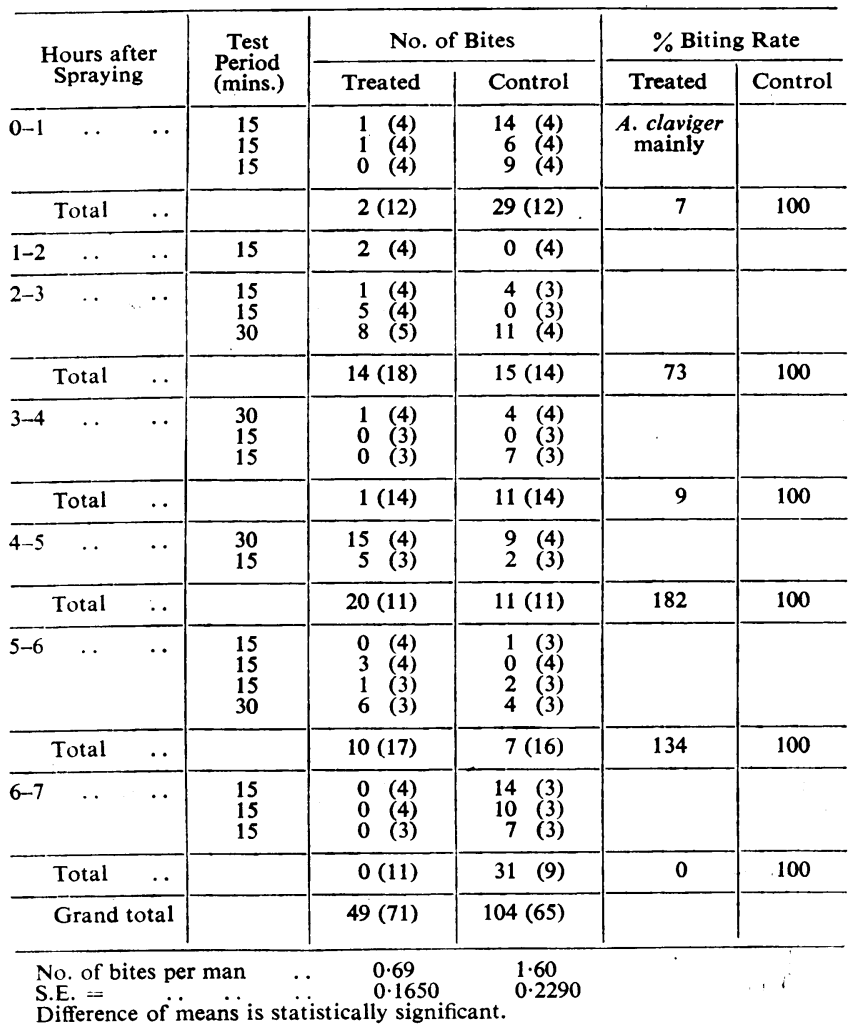

From the results shown in Table II it is evident that no great protection is afforded, and that spraying the clothing is not a reliable method of protecting exposed and otherwise unprotected parts of the body. Sometimes the controls were bitten more often and sometimes the treated, but on the whole, as shown by the grand total, a degree of protection is given. This does not bear an obvious relation to time over a sevenhour period.

From these preliminary tests it seems that lethane shows considerable promise in affording protection to those parts of the body immediately underneath the treated cloth, but that it is unreliable if a general protection by spraying all the clothing is required.

I acknowledge with thanks the grant received from the E. $L$. Hamilton Memorial Fund at the Ross Institute to enable me to prepare wartime work for publication. Thanks are also due to the Director of Hygiene, the War Office, for his permission to publish these results.

\section{G. Johnson, D.Sc.,} Ross Institute of Tropical Hygiene.

\section{New Westergren Technique}

The following technique for the Westergren sedimentation rate has been found useful. It is simple once it has been mastered; it avoids the necessity of putting lip to tube, and is of value when only a few tests are made-for example, in the ward or consulting-room.

A 2-ml. or Westergren syringe is used, and the sodium citrate is drawn up to the approximate mark-i.e., $0.4 \mathrm{ml}$.- the blood is then drawn up to the $2 \mathrm{ml}$. level and the needle withdrawn from the vein in the usual way. The plunger is pulled out to the full range, giving an air space in the syringe. By rocking the syringe, with the needle attached, the blood and the citrate are mixed. The syringe, with the needle still attached, is then held vertically with a small piece of cotton-wool over the orifice, and ail air bubbles are expelled.

The syringe is held in the right hand between the tips of the index and middle fingers, with the thumb on the plunger (a stiff syringe is better controlled by holding it between the tips of these fingers and the thumb, with the plunger held against the base of the index finger, and using a squeezing motion). The sedimentation tube is held between the thumb and the last three fingers of the left hand, leaving the index finger free to cover the end. Both the tube and the syringe are held horizontally ; the tube may need a slight downward tilt, and the needle is introduced $2-3 \mathrm{~mm}$. into the tube, using a little rotary action of the needle at the orifice to smear the blood round the lumen; the plunger is now pressed home slowly. The blood will run up the tube; on reaching the $200 \mathrm{~mm}$. mark the index finger of the left hand immediately seals the orifice. The needle is then withdrawn and the tube placed in the rack.

It is essential to have a clean tube, otherwise the blood will leave bubbles along the sides and will not run up the tube. I use a small pledget of wool pushed through the tube by two common wooden aural applicators.

\section{E. H. Hudson, M.B., F.R.C.P.}

\section{The "Innocent" Systolic Murmur}

The following example may be of interest as testifying to the "innocence" of a certain type of systolic murmur, remaining unchanged and symptomless over a period of 26 years.

\section{CASE History}

A solicitor aged 30 consulted me on July 13, 1920. He stated he had made several attempts to enter the Forces during the war of 1914-18 and had been rejected by no fewer than five medical boards in turn on diagnosis of V.D.H. and congenital heart disease. Alarmed at this he sought to know his true position and how to order his future life.

His previous history was uneventful. He gave a vague statement of having rheumatic pains during school-days, but had no serious illness of any kind. He had led a normal active life from childhood, through adolescence, to manhood, and was completely unconscious of any symptoms referable to the heart.

On examination there was no clinical enlargement of the heart; the apex was well within the nipple line. No thrill could be felt. There was a loud rasping systolic murmur heard over the whole praecordium, maximal over the pulmonary area. The murmur varied slightly on respiration but not on change of posture; and ended in a curious " click" suggestive of an exocardial origin. The pulse rate was 84 (nervous under examination); blood pressure $140 / 80$; and the response to an exercise test was good. I gave the opinion that his murmur had no pathological significance, and advised him to ignore it and carry on his normal life-an opinion which was corroborated subsequently by Prof. Wardrop Griffith of Leeds.

I saw him again over a year later, on Nov. 16, 1921, when he was contemplating insuring his life. I found his condition unchanged, and advised him to propose for insurance. He did so, and was accepted with a premium loading of $10 \%$.

Recently, 26 years later, I have had the opportunity of examining him again, on July 22, 1946. Now at the age of 56 , he leads a life of normal activity for a man of his years and has no discomfort or distress with moderate exercise nor any symptoms attributable to the heart. The physical signs remain unchanged; no enlargement of the heart; no thrill; systolic murmur loud and rasping, as before, with the same curious terminal click; pulse rate 96 ; B.P. $170 / 80$ (heart under nervous excitation due to examination).

\section{COMMENT}

During the first world war many similar cases having an innocent systolic murmur were turned down as unfit for service, labelled V.D.H., and suffered a lifelong disability in consequence. In the recent war the insignificance of this murmur has been widely recognized by medical boards. Nevertheless, from experience gained in service as medical specialist on pensions boards it would seem that not a few cases have slipped through the meshes of the net.

Harrogate WILFRID EDGECOMBE, M.D., F.R.C.P., F.R.C.S. 